\title{
Fabrication of chitosan-magnetite nanocomposite strip for chromium removal
}

\author{
Vaishnavi Sureshkumar $^{1}$ - S. C. G. Kiruba Daniel ${ }^{1} \cdot$ K. Ruckmani ${ }^{2}$. \\ M. Sivakumar ${ }^{1}$
}

Received: 18 February 2015/Accepted: 6 March 2015/Published online: 22 March 2015

(C) The Author(s) 2015. This article is published with open access at Springerlink.com

\begin{abstract}
Environmental pollution caused by heavy metals is a serious threat. In the present work, removal of chromium was carried out using chitosan-magnetite nanocomposite strip. Magnetite nanoparticles $\left(\mathrm{Fe}_{3} \mathrm{O}_{4}\right)$ were synthesized using chemical co-precipitation method at $80^{\circ} \mathrm{C}$. The nanoparticles were characterized using UVvisible spectroscopy, fourier transform infrared spectroscopy, X-ray diffraction spectrometer, atomic force microscope, dynamic light scattering and vibrating sample magnetometer, which confirm the size, shape, crystalline nature and magnetic behaviour of nanoparticles. Atomic force microscope revealed that the particle size was $15-30 \mathrm{~nm}$ and spherical in shape. The magnetite nanoparticles were mixed with chitosan solution to form hybrid nanocomposite. Chitosan strip was casted with and without nanoparticle. The affinity of hybrid nanocomposite for chromium was studied using $\mathrm{K}_{2} \mathrm{Cr}_{2} \mathrm{O}_{7}$ (potassium dichromate) solution as the heavy metal solution containing $\mathrm{Cr}(\mathrm{VI})$ ions. Adsorption tests were carried out using chitosan strip and hybrid nanocomposite strip at different time intervals. Amount of chromium adsorbed by chitosan strip and chitosan-magnetite nanocomposite strip from
\end{abstract}

V. Sureshkumar and S. C. G. Kiruba Daniel contributed equally.

K. Ruckmani

hodpharma@gmail.com

M. Sivakumar

muthusiva@gmail.com

1 Division of Nanoscience and Technology, Anna University, BIT campus, Tiruchirappalli, India

2 Department of Pharmaceutical Technology, DST Sponsored National Facility for Drug Development for Academia, Pharmaceutical and Allied Industries, Anna University, BIT Campus, Tiruchirappalli 620024, Tamilnadu, India aqueous solution was evaluated using UV-visible spectroscopy. The results confirm that the heavy metal removal efficiency of chitosan-magnetite nanocomposite strip is $92.33 \%$, which is higher when compared to chitosan strip, which is $29.39 \%$.

Keywords Magnetite nanoparticles - Chitosan · Chitosan-magnetite nanocomposite strip · Chromium

\section{Introduction}

Heavy metals like $\mathrm{Hg}$ (II), $\mathrm{Pb}$ (II), Cd (II) and $\mathrm{Cu}$ (II) are harmful because they are non-biodegradable in nature, long half-life, and get accumulated in different parts resulting in environmental pollution, of which, chromium is one of the most lethal heavy metal. Chromium exists in two forms namely the trivalent (III) and hexavalent (VI) form. $\mathrm{Cr}(\mathrm{VI})$ is considered to be more carcinogenic. The industrial sources of $\mathrm{Cr}(\mathrm{VI})$ primarily include alloy and steel manufacturing, metal finishing, electroplating, leather tanning, pigments and dyeing industries. The effluents from these industries contain $\mathrm{Cr}(\mathrm{III})$ and $\mathrm{Cr}(\mathrm{VI})$ at concentrations ranging from tenths to hundreds of ppm (Mcbain et al. 2008). Hexavalent chromium usually exists in water as oxyanions such as chromate $\left(\mathrm{CrO}_{4}^{2}\right)$ and dichromate $\left(\mathrm{Cr}_{2} \mathrm{O}_{7}{ }^{2-}\right)$ and does not precipitate easily using the conventional methods (Campo et al. 2005).

There are a number of methods reported for the removal of heavy metals, such as ion exchange (Deng et al. 2005), filtration (Chen et al. 2005), precipitation (Chang and Chen 2005), membrane process, reverse osmosis ( $\mathrm{Xu}$ et al. 2012), sedimentation and electrochemical treatment (Kim et al. 2001). Out of all the process, the membrane adsorption technique is the most preferable one for heavy 
metal ion removal. There are a variety of bio-adsorbents, but these bio-adsorbents have low adsorption capacities and slow process kinetics. So, there is a need to develop an innovative adsorbent useful for industry and which is ecofriendly.

Chitosan is being utilized for water purification process for a long time because of its properties such as polymeric nature, biodegradable and non-toxic. It is the second most abundant material in the environment next to cellulose. Chitosan has amine functional group that reacts strongly with metal ions and has a high potential of removing heavy metals as it binds the metal ions easily. The main objective of the present work was (i) to remove $\mathrm{Cr}(\mathrm{VI})$ from aqueous solution, (ii) to show that the removal efficiency of chromium by chitosan-magnetite nanocomposite strip is greater, (iii) to prove that the nanocomposite strip is a costeffective and simple process. It is proposed here to make nanocomposite strip using chitosan and magnetite nanoparticles. Chitosan-magnetite nanocomposite strip follows physicochemical adsorption process to remove $\mathrm{Cr}(\mathrm{VI})$. The unique properties of magnetite nanoparticles are they have high surface area-volume ratio, extremely small size, surface modifiability, excellent magnetic properties and great biocompatibility. Earlier studies have been done on magnetite nanoparticles to investigate its adsorption capacity towards heavy metals (Martínez-Mera et al. 2007; Yuan et al. 2010; Adikary and Sewvandi 2011). Also, chitosan, a biopolymer, which is extracted from crustacean shells or from fungal biomass, has high porosity resulting in superior binding properties for metal ion such as cadmium, copper, lead, uranyl, mercury and chromium (Zheng et al. 2007; Han et al. 2012; Recep and Ulvi 2008; Shilpi et al. 2011; Yue et al. 2011). Magnetite nanoparticles with chitosan would possibly have better heavy metal removal. Hence, it is planned that magnetic nanoparticles could be introduced in chitosan for the heavy metal removal in aqueous stream. The synergistic effect of chitosan along with magnetite nanoparticles in removing chromium has also been studied in this report.

\section{Materials and methods}

Reagents such as ferrous sulphate $\left(\mathrm{Fe}_{2} \mathrm{SO}_{4} \cdot 7 \mathrm{H}_{2} \mathrm{O}\right)$, ferric chloride $\left(\mathrm{FeCl}_{3} \cdot 6 \mathrm{H}_{2} \mathrm{O}\right)$, sodium hydroxide $(\mathrm{NaOH})$, potassium dichromate $\left(\mathrm{K}_{2} \mathrm{Cr}_{2} \mathrm{O}_{7}\right)$ and glacial acetic acid $(99 \%$ pure) were purchased from Sigma-Aldrich with high purity. Chitosan [mol. wt: $375 \mathrm{kDa}$, viscosity: $200-800 \mathrm{Kcps}$; $90 \%$ deacetylated; soluble in dilute aqueous acid ( $\mathrm{pH}<6.5)$ ] is also purchased from Sigma-Aldrich. Synthesized nanoparticles were characterized by UV-visible spectrophotometer (JASCO V 650), Fourier transform infrared spectroscopy-Perkin Elmer Spectrum RX I FTIR instrument, X-Ray diffraction-Rigaku Ultima III XRD, dynamic light scattering-Malvern Zetasizer V 6.20 series, atomic force microscope-Park AFM XE-100 and vibrating sample magnetometer-VSM model 7404, respectively. The casted chitosan-magnetite strip was characterized using FESEM EDX instrument. Heavy metal ion-removed aqueous samples were analysed using UV-visible spectrophotometer (JASCO V 650).

\section{Synthesis of magnetite nanoparticles $\left(\mathrm{Fe}_{3} \mathrm{O}_{4}\right)$}

Magnetite $\left(\mathrm{Fe}_{3} \mathrm{O}_{4}\right)$ nanoparticles were synthesized by chemical co-precipitation method. The concentrations of ferrous sulphate:ferric chloride precursors are $0.75 \mathrm{M}$ each. The precursors are taken in 2:1 ratio and stirred well for $15 \mathrm{~min}$. After $15 \mathrm{~min}$ of stirring, sodium hydroxide is added at regular intervals to the precursor solution. Upon addition of $\mathrm{NaOH}$, the solution turned black, indicating the formation of magnetite nanoparticles. Further stirring is continued for $1 \mathrm{~h}$ to uniformly disperse the magnetic nanoparticles. The nanoparticles were centrifuged and washed with deionised water. The magnetite powder obtained was then dispersed into deionised water and used for the experiment (Fig. 1). The entire reaction is given by the equation as follows:

$\mathrm{Fe}^{2+}+2 \mathrm{Fe}^{3+}+8 \mathrm{OH}^{-} \longrightarrow \mathrm{Fe}_{3} \mathrm{O}_{4}+4 \mathrm{H}_{2} \mathrm{O}$

\section{Fabrication of Chitosan-magnetite nanocomposite strip}

One wt $\%$ of chitosan is dissolved in 1 vol\% glacial acetic acid. The chitosan solution was sonicated for $15 \mathrm{~min}$, and the solution was allowed to stir for $18 \mathrm{~h} .0 .05 \mathrm{~g}$ of magnetite nanoparticles was added to the chitosan solution and stirred again for $6 \mathrm{~h}$ to get chitosan-magnetite

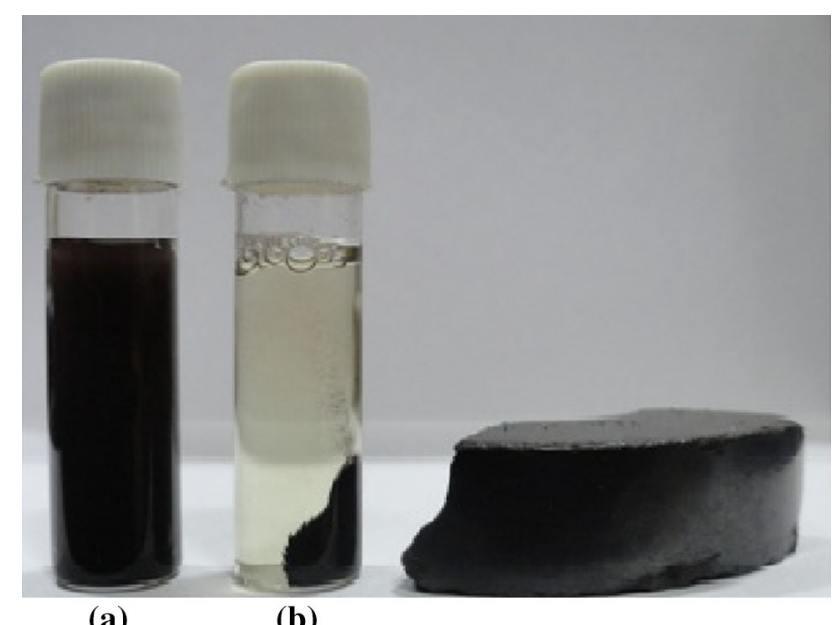

Fig. 1 Magnetite nanoparticles (a) Magnetite nanoparticles attracted by an external magnet (b) 
Fig. 2 Schematic representation of fabrication of hybrid strip (chitosan-magnetite nanocomposite) using solution casting method

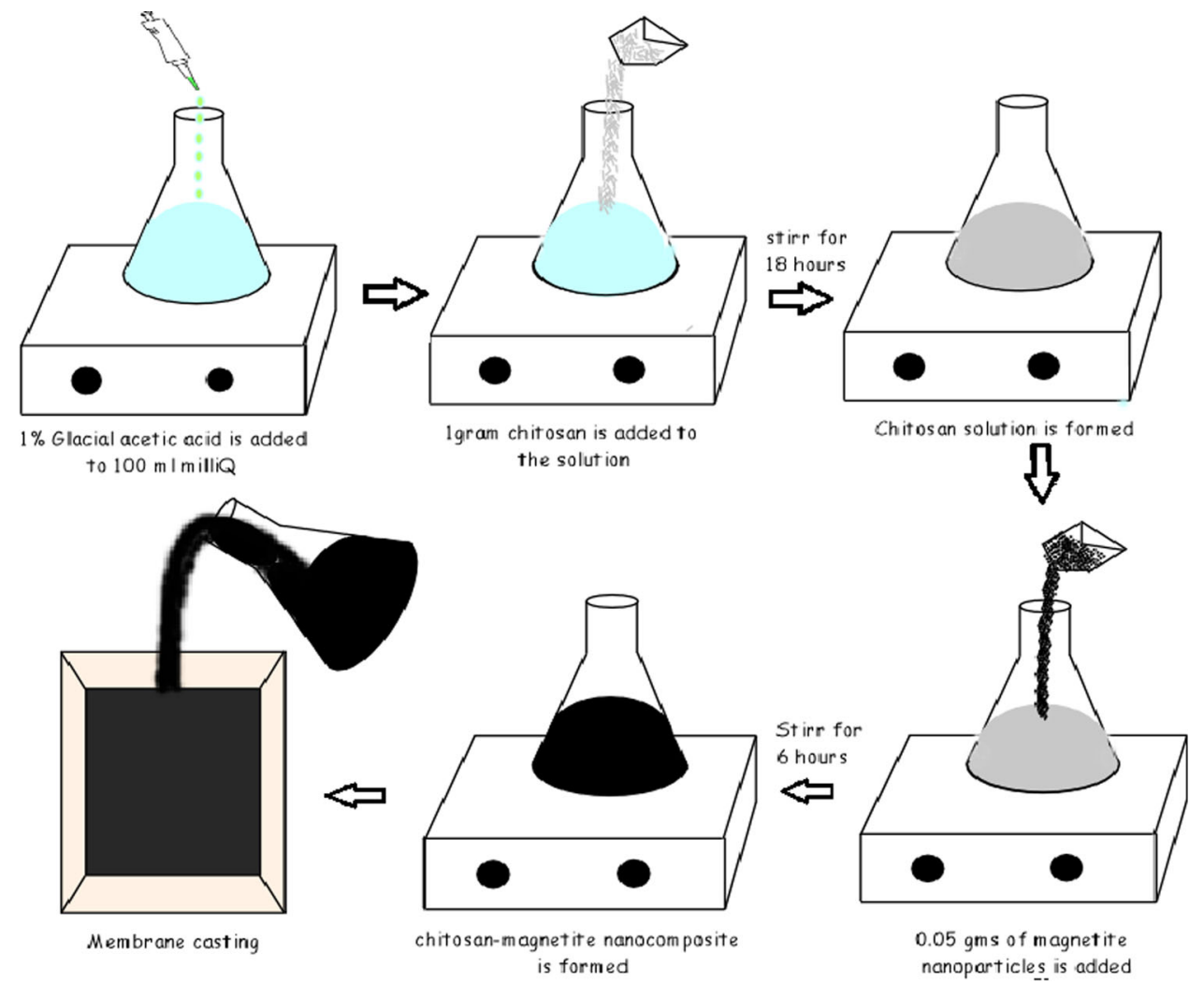

nanocomposite strip. Aqueous solution of chromium was prepared from potassium dichromate $\left(\mathrm{K}_{2} \mathrm{Cr}_{2} \mathrm{O}_{7}\right)$. The concentration of the heavy metal solution is $5 \mathrm{mM}$ in $30 \mathrm{ml}$ deionised water. The aqueous solution $(30 \mathrm{ml})$ was prepared and divided into $10 \mathrm{ml}$ each. The chitosan strip and nanocomposite strip cut into $1 \mathrm{~cm} \times 1 \mathrm{~cm}$ are dropped in $10 \mathrm{ml}$ solution each. The adsorption experiments were carried out, and the reduction in the concentration of the aqueous solution was recorded at regular time intervals. The chitosan and nanocomposite strip swell, indicating that the heavy metal ions are adsorbed onto the strip. The heavy metal removal efficiency of chitosan strip and nanocomposite strip was evaluated using UV-visible spectroscopy.

\section{Results and discussion}

\section{UV-visible and FTIR spectroscopy}

Iron oxides, such as magnetite, exhibit thermally induced electron delocalization between $\mathrm{Fe}^{2+}$ and $\mathrm{Fe}^{3+}$ ions. The UV-visible peak for magnetite nanoparticles was obtained at $407 \mathrm{~nm}$ (Fig. 4). The reported UV-visible peak was found to be $404 \mathrm{~nm}$ (Rahman et al. 2011), and result obtained in the experiment was $407 \mathrm{~nm}$. From the data obtained, the peak in the near IR region confirms the presence of magnetite $\left(\mathrm{Fe}_{3} \mathrm{O}_{4}\right)$ nanoparticles. When magnetite is

was studied using chitosan strip and chitosan-magnetite 


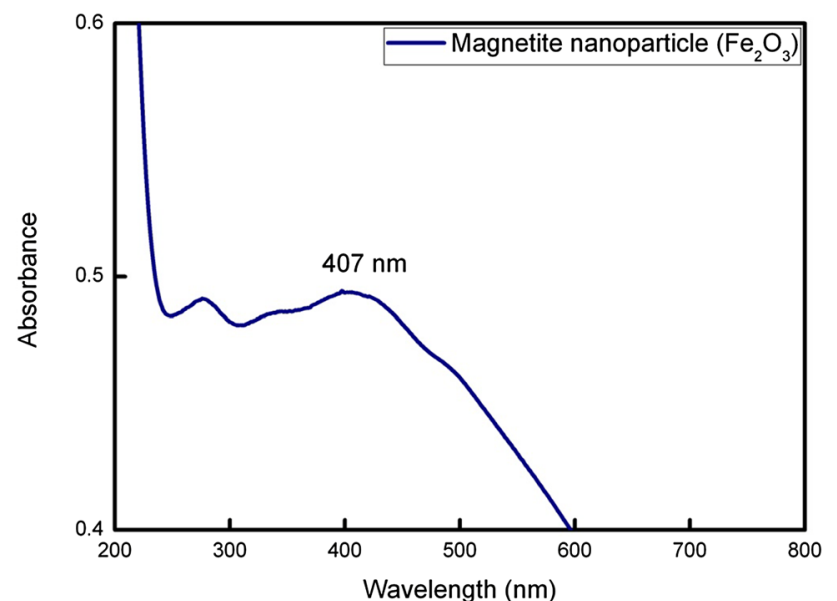

Fig. 4 UV-visible absorption spectroscopic analysis of the synthesized magnetite nanoparticles exhibiting peak at $407 \mathrm{~nm}$

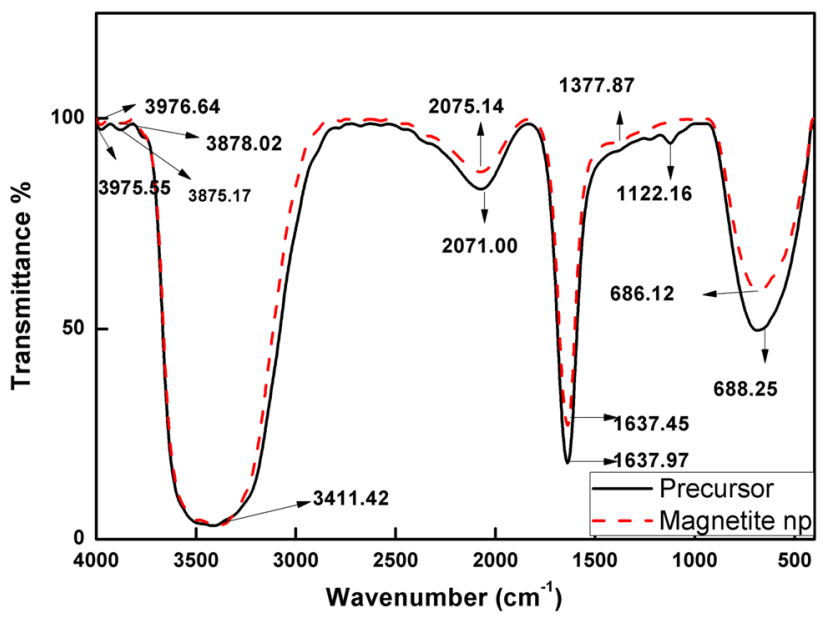

Fig. 5 FTIR analysis of the precursor solution (ferrous sulphate:ferric chloride) and magnetite nanoparticles

oxidized, it becomes maghemite nanoparticles and the UV$\mathrm{V}$ peak is expected to decrease because of no absorption in the near IR region.

FTIR was analysed for the ferric chloride:ferrous sulphate mixture and $\mathrm{Fe}_{3} \mathrm{O}_{4}$ nanoparticles (Fig. 5). The strong absorption band at $684 \mathrm{~cm}^{-1}$ is assigned to the vibrations of the $\mathrm{Fe}-\mathrm{O}$ bond, which confirm the formation of $\mathrm{Fe}_{3} \mathrm{O}_{4}$ nanoparticles. Previously, it was reported that the characteristic absorption band for $\mathrm{Fe}-\mathrm{O}$ in bulk $\mathrm{Fe}_{3} \mathrm{O}_{4}$ appeared at 570 and $375 \mathrm{~cm}^{-1}$ wavenumber (Waldon 2008). However, in the present case, the band for $\mathrm{Fe}-\mathrm{O}$ shifts towards higher wavenumber ${ }^{18}$ of $686 \mathrm{~cm}^{-1}$. It is due to the breaking of the large number of bands for surface atoms, resulting in the rearrangement of localized electrons on the particle surface, and the surface bond force constant increases as $\mathrm{Fe}_{3} \mathrm{O}_{4}$ is reduced to nanoscale dimension, so that the absorption bands shift to higher wavenumber. The broad absorption at



Fig.. 6 X-ray diffraction analysis for the synthesized magnetite nanoparticles exhibiting characteristic peaks of plane (311) of matching with JCPDS file no: 19-0629

$3421 \mathrm{~cm}^{-1}$ corresponds to the overlapping stretching vibrations of aromatic $\mathrm{OH}^{-}$group and aromatic hydrogen and $\mathrm{NH}$ groups. The wavenumber at $1646 \mathrm{~cm}^{-1}$ corresponds to $\mathrm{C}=\mathrm{O}$ stretching vibration (Shilpi et al. 2011).

\section{X-Ray diffraction analysis}

Figure 6 illustrates the XRD patterns of magnetic nanoparticles. It is clear from the graph that only the $\mathrm{Fe}_{3} \mathrm{O}_{4}$ phase is of highly crystalline nature. The position and relative intensity of all diffraction peaks match well with those of the magnetite (JCPDS file no: 19-0629), and broad peaks indicate the nano-crystalline nature of the particles (Guin and Manorama 2008) having face-centred cubic inverse spinel structure. No peaks of any other phases are observed in the XRD patterns, indicating the high purity of the products. As reported earlier (Pattnaik 2011), black colour of the nanoparticles indicates the presence of magnetite phase and not maghemite phase. The diffraction peak (311) plane corresponds to the magnetite nanoparticles; the $2 \theta$ value is 35.7 .

\section{Stability of magnetite nanoparticles}

Zeta potential indicates the degree of repulsion between adjacent, similarly charged particles in the dispersion and the stability of the particles in the dispersion. The zeta potential value of the $\mathrm{Fe}_{3} \mathrm{O}_{4}$ nanoparticles was found to be $-16.5 \mathrm{mV}$ (Fig. 7). Report indicates that the magnetite nanoparticles are stable in the dispersion.

\section{Morphology of magnetite nanoparticles}

To investigate the morphology and monodispersity of magnetite nanoparticles, AFM analysis has been done. 
Fig. 7 Zeta potential analysis of the synthesized magnetite nanoparticles exhibiting value of $-16.5 \mathrm{mV}$

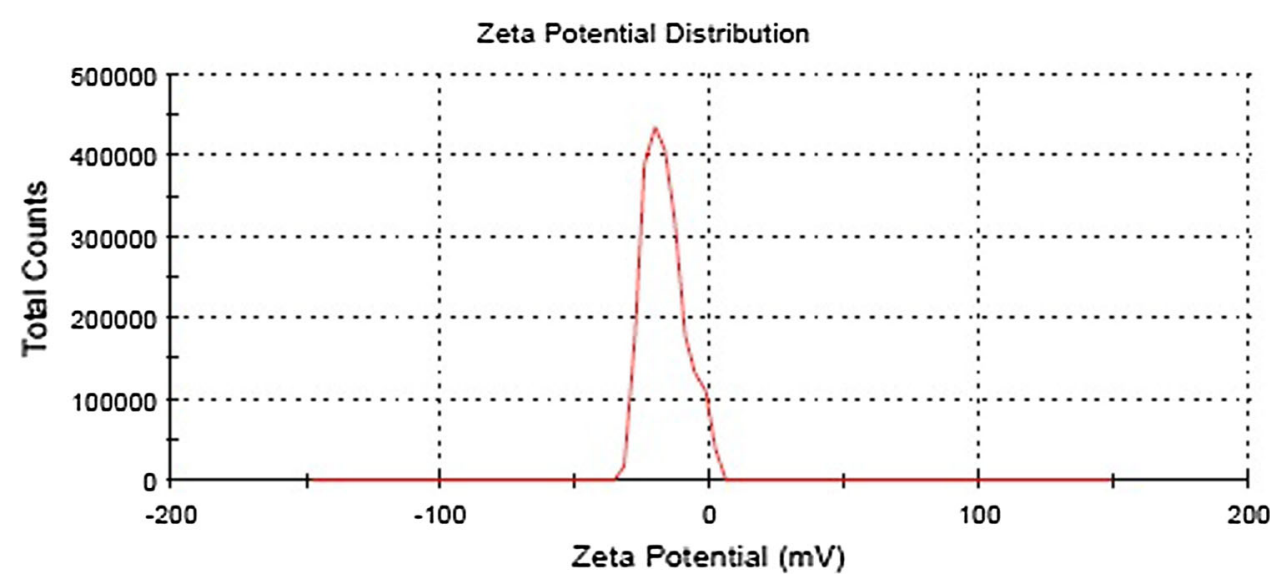

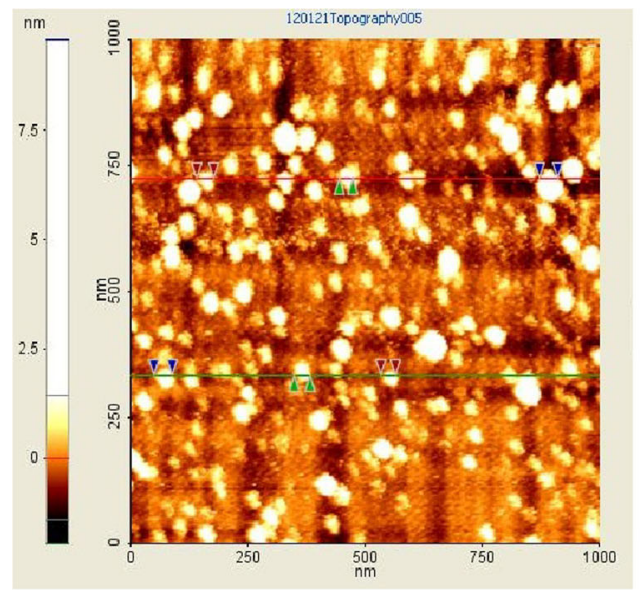

(a)

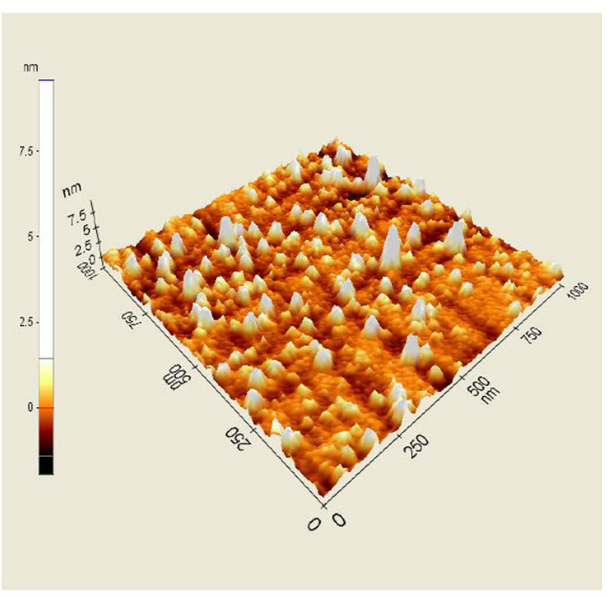

(b)



(c)

Both two-dimensional and three-dimensional images of magnetite nanoparticles were obtained (Fig. 8). The magnetite nanoparticles characterized by AFM reveal that the particle sizes are uniformly distributed. The particle size was found to be around $10-20 \mathrm{~nm}$. The magnetite nanoparticles were uniformly distributed. The AFM results matched with the previously published reports having a size of $35 \mathrm{~nm}$, respectively (Cai and Wan
2007). AFM image is analysed using $\mathbf{J}$ image software to interpret the diameter of individual nanoparticle. The cumulative result is then plotted as a histogram. The results show that the nanoparticles are spherical in shape. From the histogram data, the number of nanoparticles in each size range has been found, with a maximum number of nanoparticles having a size of $10-15 \mathrm{~nm}$. 


\section{Magnetic behaviour of magnetite nanoparticles}

Vibrating sample magnetometer predicts the magnetic behaviour of nanoparticles. Figure 9 gives the magnetization loop for magnetite nanoparticles at room temperature. The magnetic hysteresis curve exhibits the superparamagnetic behaviour. The material exhibits a narrow hysteresis curve with a small value of coercivity and retentivity. VSM results show that the coercivity (Hci), which is the field required to magnetize the material, is 61.172 Oe and retentivity $(\mathrm{Mr})$, which is the field required to demagnetize the material, is $5.4324 \mathrm{emu} / \mathrm{g}$. The saturation magnetization value of the magnetite nanoparticles was found to be $70.787 \mathrm{emu} / \mathrm{g}$, which indicates that above this value, the material cannot be magnetized. The above-obtained results corroborated with the earlier reports (Sundrarajan and Ramalakshmi 2012), where the magnetization value is $41.5 \mathrm{emu} / \mathrm{g}$. From the hysteresis loop obtained, it is clear that magnetite nanoparticle has the properties of a soft magnet that can easily magnetize and demagnetize.

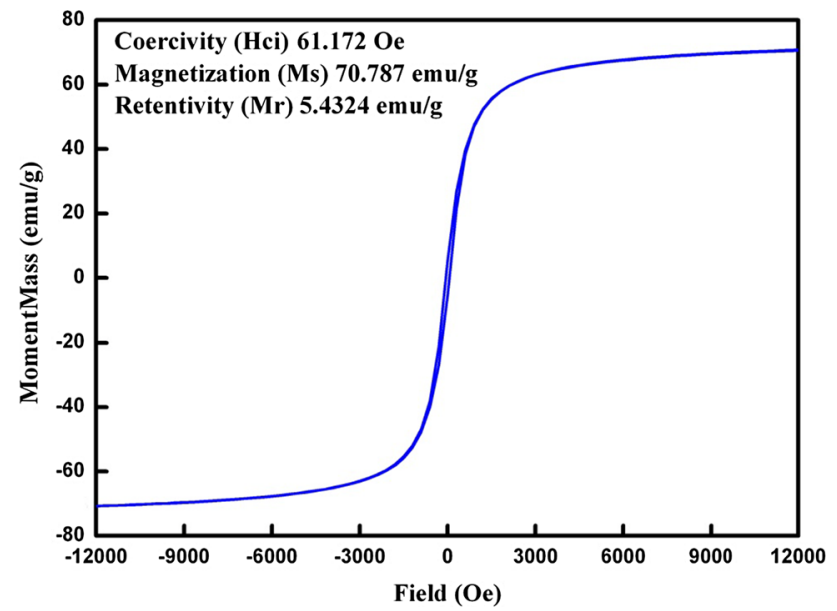

Fig. 9 Vibrating sample magnetometer analysis of magnetite nanoparticles exhibiting the coercivity (Hci) and retentivity (Mr) value of magnetite nanoparticles as $61.172 \mathrm{Oe}$ and $5.4324 \mathrm{emu} / \mathrm{g}$, respectively

Fig. 10 FESEM image of chitosan-magnetite nanocomposite strip (a) EDX spectra of nanocomposite strip (b)

\section{FESEM-EDX analysis for nanocomposite strip}

The FESEM results (Fig. 10a) show that the nanoparticles are distributed in the chitosan strip. The nanoparticles are spherical in shape and are evenly distributed. The number and energy of the X-rays emitted from a specimen can be measured by an energy-dispersive spectrometer. The electron dispersive spectroscopy (EDS) analysis of these particles indicates the presence of $\mathrm{Fe}$ and $\mathrm{O}$ composition in the chitosan-magnetite nanocomposite strip (Fig. 10b). The elemental composition of iron, oxygen and carbon is $52.71,34.88$ and $43.54 \%$, respectively. The results obtained matched with the previous reports, where the composition of iron and oxygen in iron oxide nanoparticles was found to be 54.11 and $45.88 \%$, respectively. No other peak related to any impurity has been detected in the EDS, which confirms that the grown nanoparticles in the nanocomposite strip are composed only with iron and oxygen and carbon. Thus, the presence of iron content in the nanocomposite strip was confirmed from the EDX results.

\section{Studies on $\operatorname{Cr}(\mathrm{VI})$ removal}

The removal of chromium [Cr(VI)] ions from the aqueous solution was evaluated using chitosan-magnetite nanocomposite and chitosan strips. Chitosan strip is kept as the control. Due to the better dispersion performance of magnetite nanoparticles, they are chosen for the adsorption tests in this study. The removal of $\mathrm{Cr}$ (VI) was done using UV-visible absorption spectrophotometer (JASCO V 650) at different time intervals (Fig. 11). From the values of absorbance obtained, it is known that chitosan removes chromium ions, but chitosan-magnetite nanoparticles were highly efficient in the removal of chromium ions [Cr(VI)]. From this, it is clear that the nanocomposite has a greater efficiency than chitosan strip in the removal of chromium (VI). The graph obtained, when compared to earlier studies $^{3}$, shows that chromium uptake by $\mathrm{Fe}_{3} \mathrm{O}_{4}$ nanoparticles is a physicochemical process, including electrostatic

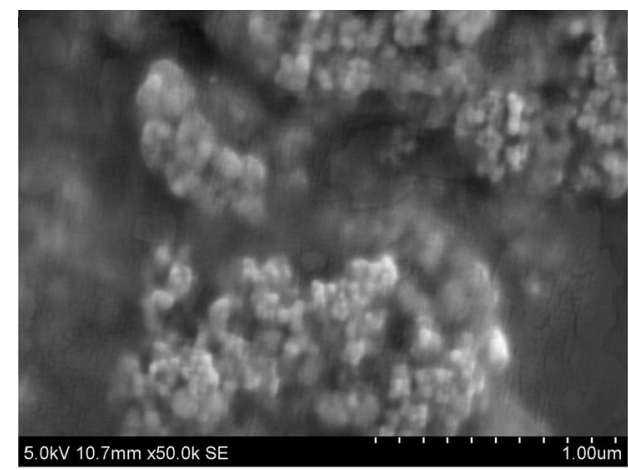

(a)

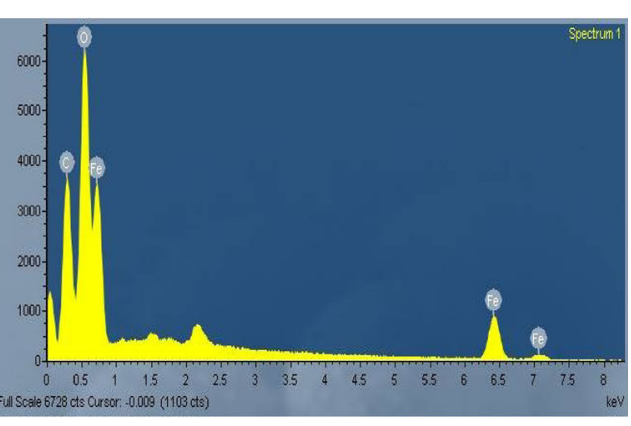

(b) 


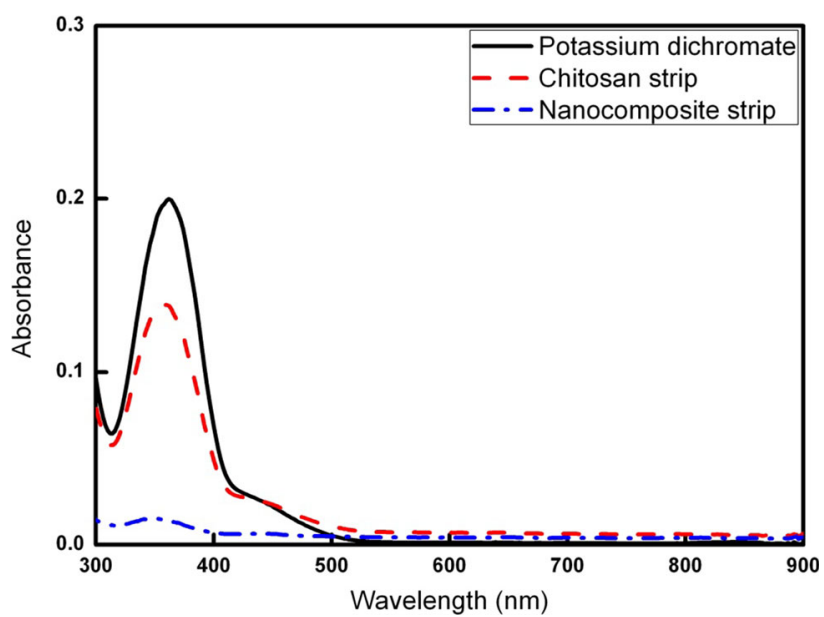

Fig. 11 UV-visible spectroscopic analysis of removal of chromium from the aqueous solution by hybrid strip

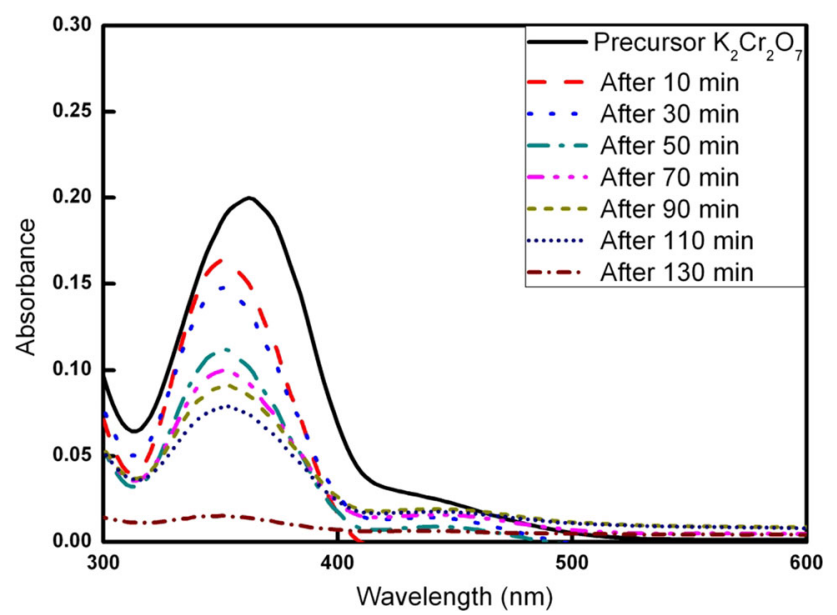

Fig. 12 UV-visible spectroscopic results for the adsorption kinetics of $\mathrm{Cr}(\mathrm{VI})$ removal using nanocomposite strip at regular time intervals

interaction followed by redox process where the $\mathrm{Cr}(\mathrm{VI})$ is reduced to $\mathrm{Cr}(\mathrm{III})$. Adsorption kinetics was studied to understand the removal of $\mathrm{Cr}(\mathrm{VI})$ ions from $\mathrm{K}_{2} \mathrm{Cr}_{2} \mathrm{O}_{7}$ solution (Fig. 12). UV-visible spectroscopic results were obtained for the aqueous heavy metal solution, and it was compared with the chitosan-magnetite nanocomposite strip at regular time intervals such as 10, 30, 50, 70, 90, 110 and $130 \mathrm{~min}$, respectively. Maximum adsorption of $\mathrm{Cr}(\mathrm{VI})$ is obtained at $130 \mathrm{~min}$. The regular decrease in the value of absorbance shows the removal of $\mathrm{Cr}(\mathrm{VI})$ ions at each time interval. The removal of efficiency of chitosan and chitosan-magnetite nanocomposite strip is plotted against time in Fig. 13. From the above results, it is noted that the removal efficiency of chitosan strip is $29.39 \%$, and that of the chitosan-magnetite nanocomposite strip is $92.33 \%$. The removal efficiency is calculated using the formula

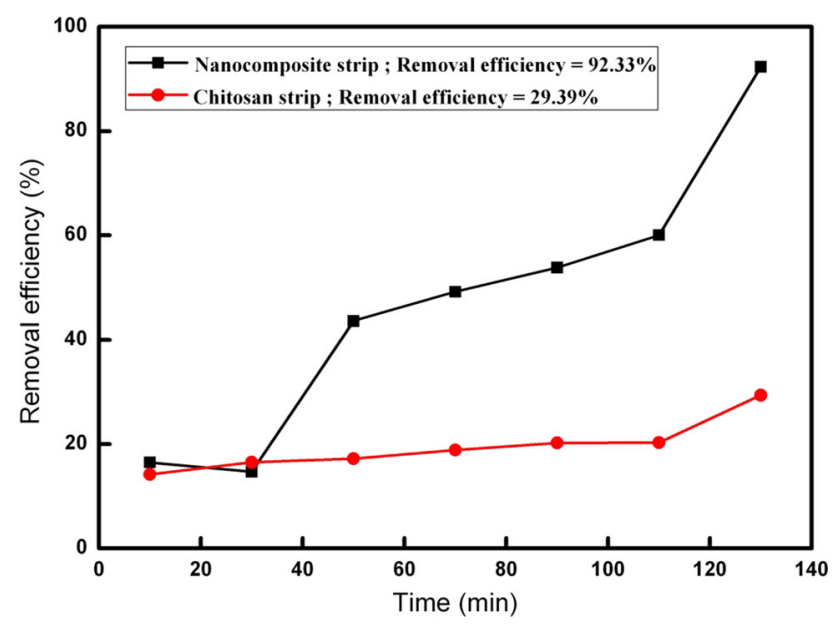

Fig. 13 Graph showing the removal efficiency of chitosan strip and chitosan-magnetite nanocomposite with relation to time

$E=\left(C_{0}-C_{t} / C_{0}\right) \times 100$. Therefore, the nanocomposite strip enhances $62.94 \%$ than the chitosan strip.

\section{Mechanism of adsorption and chromium removal}

Adsorption is a mass transfer process in which a substance is transferred from the liquid phase to the surface of a solid. Chitosan is a biopolymer that has protonated amine groups, hydroxyl and carboxylates, which serve as active binding sites for metal ions (Guibal 2004). $\mathrm{Fe}_{3} \mathrm{O}_{4}$ nanoparticles are negatively charged and have large surface area leading to increased adsorption efficiency (Nirmala 2014). Negatively charged $\mathrm{Fe}_{3} \mathrm{O}_{4}$ nanoparticles bind to chitosan, which is positively charged to form chitosan-magnetite nanocomposite (Xiaowang Liu et al. 2008). Chromium(VI) exists in aqueous solutions as $\mathrm{Cr}_{2} \mathrm{O}_{7}{ }^{2-}, \mathrm{HCrO}^{-}{ }^{-} \mathrm{CrO}_{4}{ }^{2-}$ and $\mathrm{HCr}_{2} \mathrm{O}_{7}{ }^{-}$. When chitosanmagnetite nanocomposite strip is dropped into aqueous $\mathrm{K}_{2} \mathrm{C}_{2} \mathrm{O}_{7}$ solution, dichromate ions which are negatively charged bind with the cationic amine groups of chitosan, resulting in electrostatic attraction. This is followed by ion exchange process, where $\mathrm{Cr}(\mathrm{VI})$ ions replace the adsorbed $\mathrm{H}^{+}$ions from $\mathrm{Fe}_{3} \mathrm{O}_{4}$ surface (Shetty 2006) as described in the scheme (Fig. 14). During the redox process, $\mathrm{Cr}(\mathrm{VI})$ is reduced to $\mathrm{Cr}(\mathrm{III})$, resulting in the removal of chromium. At low pH (2-3), electrostatic attraction takes place, resulting in adsorption, and at high $\mathrm{pH}$, electrostatic repulsion takes place, leading to desorption.

\section{Conclusion}

Magnetite nanoparticles are synthesized using chemical coprecipitation method. UV-visible spectrum of magnetite nanoparticles showed the $\lambda_{\max }$ at $407 \mathrm{~nm}$. The particle size 




Fig. 14 Schematic representation of mechanism behind the removal of chromium by chitosan-magnetite nanocomposite strip

was found to be $15-30 \mathrm{~nm}$ and spherical in shape as analysed under atomic force microscope. FTIR analysis exhibited a characteristic band at $684 \mathrm{~cm}^{-1}$, which is specific for $\mathrm{Fe}-\mathrm{O}$ bonding to indicate the presence of $\mathrm{Fe}_{3} \mathrm{O}_{4}$ nanoparticles. XRD analysis shows the diffraction peak at (311) lattice plane, which is the plane for magnetite nanoparticles. Vibrating sample magnetometer results indicated the coercivity (Hci) and retentivity (Mr) value of magnetite nanoparticles as $61.172 \mathrm{Oe}$ and $5.4324 \mathrm{emu} / \mathrm{g}$, respectively. The magnetization value of the magnetite nanoparticles is $70.787 \mathrm{emu} / \mathrm{g}$. From the hysteresis loop, it is confirmed that the synthesized magnetite nanoparticle is a soft magnet that can be magnetized and demagnetized quickly. From the FESEM results for the chitosan-magnetite nanocomposite strip, the elemental composition was found to be iron having a weight percentage of $52.71 \%$. Chitosan-magnetite nanocomposite strip and chitosan strip were evaluated for the removal of chromium from $\mathrm{K}_{2} \mathrm{Cr}_{2} \mathrm{O}_{7}$ (potassium dichromate) solution. The adsorption tests at different time intervals were recorded, and the removal efficiency of chitosan and chitosan-magnetite nanocomposite strip was plotted. The chromium removal efficiency of chitosan strip is $29.39 \%$, and that of the chitosanmagnetite nanocomposite strip is $92.33 \%$. Therefore, the nanocomposite strip has enhanced $62.94 \%$ more than the control chitosan strip. Thus, it can be concluded that the removal efficiency of chromium using chitosan-magnetite nanocomposite strip is highly efficient, and studies are being performed for further improvement in treating tannery effluents.

Acknowledgments Vaishnavi Sureshkumar thanks UGC for providing Rajiv Gandhi Fellowship for the PG program. S C G Kiruba Daniel would like to acknowledge TNSCST, Government of Tamil Nadu, India, for RFRS funding. The authors gratefully acknowledge DST, New Delhi, Ministry of Science and Technology, Government of India, in the form of facility project National Facility for Drug Development for Academia, Pharmaceutical and Allied Industries.

Open Access This article is distributed under the terms of the Creative Commons Attribution License which permits any use, distribution, and reproduction in any medium, provided the original author(s) and the source are credited.

\section{References}

Adikary SU, Sewvandi GA (2011) Removal of heavy metals from wastewater using chitosan, Department of Material Science and Engineering, University of Moratuwa

Cai W, Wan J (2007) Facile synthesis of superparamagnetic magnetite nanoparticles in liquid polyols. J Colloid Interface Sci 305:366-370

Campo AD, Sen T, Lellouche JP, Bruce IJ (2005) Multifunctional magnetite and silica-magnetite nanoparticles: synthesis, surface activation and application in life sciences. J Magn Magn Mater 293:33-40

Chang YC, Chen DH (2005) Preparation and adsorption properties of monodisperse chitosan-bound $\mathrm{Fe}_{3} \mathrm{O}_{4}$ magnetic nanoparticles for removal of $\mathrm{Cu}$ (II) ions. J Colloid Interface Sci 283:446-451

Chen G, Hu J, Irene ML (2005) Removal and recovery of Cr (VI) from wastewater by maghemite nanoparticles. J Hazard Mater 2:4528-4536

Deng YH, Wang CC, Hu JH, Yang WL, Fu SK (2005) Investigation of formation of silica-coated magnetite nanoparticles via sol-gel approach. J. Colloids Surf A Physiochem Eng Asp 262:87-93

Guibal E (2004) Interactions of metal ions with chitosan-based sorbents: a review. J Sep Purif Technol 38:43-74

Guin D, Manorama VS (2008) Room temperature synthesis of monodispersed iron oxide nanoparticles. J Mater Lett 62:3139-3142

Han Y, Lingyun Y, Zhen Y, Hu Y, Aimin L, Rongshi C (2012) Preparation of chitosan/poly(acrylic acid) magnetic composite microspheres and applications in the removal of copper(II) ions from aqueous solutions. J Hazard Mater 229-230:371-380

Kim DK, ZhangY Voit W, Rao KV, Kehr J, Bjelke B, Muhammed M (2001) Superparamagnetic iron oxide nanoparticles for biomedical applications. Scripta Mater 44:1713-1717

Liu X, Hu Q, Fang Z, Zhang X, Zhang B (2008) Magnetic chitosan nanocomposites: a useful recyclable tool for heavy metal ion removal. In: Langmuir J (ed) vol 25, pp 3-8

Martínez-Mera I, Espinosa-Pesqueira ME, Pérez-Hernández R, Arenas-Alatorre $\mathbf{J}$ (2007) Synthesis of magnetite $\left(\mathrm{Fe}_{3} \mathrm{O}_{4}\right)$ nanoparticles without surfactants at room temperature. J Mater Lett 61:4447-4451

McBain SC, Yiu HHP, Dobson J (2008) Magnetic nanoparticles for gene and drug delivery. Int J Nanomed 3:169-180

Nirmala I (2014) Use of iron oxide magnetic nanosorbents for Cr (VI) removal from aqueous solutions: a review. J Eng Res Appl 4:55-63

Pattnaik A (2011) Synthesis and characterization of amine-functionalized magnetic silica nanoparticle, Doctoral dissertation

Rahman MM, Khan SK, Jamal A, Faisal M, Aisiri MA (2011) Iron oxide nanoparticles, Mohammed Rahman (ed) ISBN: 978-953307-913-4 (InTech)

Recep A, Ulvi U (2008) Adsorptive features of chitosan entrapped in polyacrylamide hydrogel for $\mathrm{Pb} 2+, \mathrm{UO} 22+$, and $\mathrm{Th} 4+$. J Hazard Mater 151:380-388

Shetty AR (2006) Metal anion removal from wastewater using chitosan in a polymer enhanced diafiltration system, A Thesis 
submitted to the Faculty of Worcester Polytechnic Institute, Degree of Master of Science in Biotechnology

Shilpi K, Padmaja PS, Sudhakar (2011) Adsorption of mercury(II), methyl mercury(II) and phenyl mercury(II) on chitosan crosslinked with a barbital derivative. Carbohydr Polym 86:1055-1062

Sundrarajan M, Ramalakshmi M (2012) Novel cubic magnetite nanoparticle synthesis using room temperature ionic liquid. J Chem 9:1070-1076

Waldon RD (2008) Infrared spectra of ferrites. J Phys Rev 1955(99): 1727

Xu P, Zengam GM, Huang DH, Feng CL, Hu S, Zhao MH, Lai C, Wei Z, Huang C, Xie GX, Liu ZF (2012) Use of iron oxide nanomaterials in wastewater treatment. J Sci Total Envir 424:1-10
Yuan P, Liu D, Fan M, Yang D, Zhu R, Ge F, Zhu JX, He HP (2010) Removal of hexavalent chromium $[\mathrm{Cr}(\mathrm{VI})]$ from aqueous solutions by the diatomite-supported/unsupported magnetite nanoparticles. J Hazard Mater 173:614-621

Yue W, Zhiru T, Yi C, Yuexia G (2011) Adsorption of Cr(VI) from aqueous solutions using chitosan-coated fly ash composite as biosorbent. Chem Eng J 175:110-116

Zheng W, Li XM, Yang Q, Zeng GM, Shen XX, Zhang J, Liu JJ (2007) Adsorption of $\mathrm{Cd}(\mathrm{II})$ and $\mathrm{Cu}$ (II) from aqueous solution by carbonate hydroxyapatite derived from egg shell waste. J Hazard Mater 147:534-539 